\title{
The use of near infrared spectroscopy (NIRS) to predict the chemical composition of feed samples used in ostrich total mixed rations
}

\author{
E. Swart $^{1,3}$, T.S. Brand ${ }^{1,2 \#}$ \& J. Engelbrecht ${ }^{4}$ \\ ${ }^{1}$ Elsenburg Institute for Animal Production, Dept of Agriculture: Western Cape, Private Bag X1, Elsenburg, 7607, \\ South Africa; ${ }^{2}$ Dept of Animal Sciences, Stellenbosch University, Private Bag X1, Matieland, 7602; \\ ${ }^{3}$ Nelson Mandela Metropolitan University, George Campus: Saasveld, Private Bag X6531, George, 6530 \\ ${ }^{4}$ Department of Physics, Nelson Mandela Metropolitan University, Port Elizabeth, 6031, South Africa
}

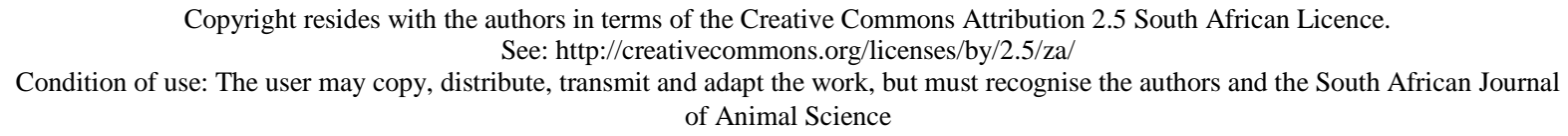

\begin{abstract}
The wet chemical analysis of feed samples is time consuming and expensive. Near infrared spectroscopy (NIRS) was developed as a rapid technique to predict the chemical composition of feeds. The prediction of accuracy of NIRS relies heavily on obtaining a calibration set which represents the variation in the main population, accurate laboratory analyses and the application of the best mathematical procedures. In this study NIRS was used to determine the chemical composition of total mixed rations (TMRs) used in ostrich diets. A sample population of 479 ostrich feed samples was used in the calibration and 94 samples were used in the independent validation of dry matter (DM), ash, crude protein (CP), ether extract (EE), crude fibre (CF), acid detergent fibre (ADF), neutral detergent fibre (NDF), gross energy (GE), calcium (Ca) and phosphorus $(\mathrm{P})$. Coefficient of determination in validation $\left(r_{\mathrm{v}}^{2}\right)$ and standard error of prediction (SEP) was satisfactory $\left(r_{\mathrm{v}}^{2}\right.$ values higher than 0.80$)$. Coefficient of determination and SEP values for CP, EE, CF, ADF, NDF and GE were $0.97 \%$ and $0.74 \%, 0.89 \%$ and $0.50 \%, 0.94 \%$ and $1.41 \%, 0.89 \%$ and $2.67 \%, 0.95 \%$ and $2.81 \%$ and $0.80 \%$ and $0.28 \mathrm{MJ} / \mathrm{kg}$, respectively. Less accurate values $\left(r^{2}\right.$ below 0.80$)$ were obtained for $\mathrm{DM}$, ash, $\mathrm{Ca}$ and $\mathrm{P}$ being $0.57 \%$ and $0.28 \%, 0.67 \%$ and $1.29 \%, 0.43 \%$ and $0.59 \%$ and $0.49 \%$ and $0.11 \%$, respectively. The study indicated that NIRS is a suitable tool for a rapid, non-destructive and reliable prediction of the chemical composition of ostrich TMRs.
\end{abstract}

Keywords: NIRS, ostrich TMR, chemical composition, nutritive value

\#Corresponding author: tersb@elsenburg.com

\section{Introduction}

For adequate feeding of livestock, farmers need information about the nutritive value of available feedstuffs (Goedhart, 1990). Livestock selected for high production require an adequate supply of nutrients. This is essential not only for the health of the animals, but also from an economic viewpoint (Givens et al., 1997). The wet chemical analyses of feed samples to determine their chemical composition are time consuming and expensive. Plant breeders, farmers and animal nutritionists require an accurate, precise, rapid and cost-effective method of assessing the nutritive value of pastures and feeds (Smith \& Flinn, 1991). Near infrared spectroscopy (NIRS) provides an opportunity to determine the chemical composition of feedstuffs. Apart from its rapidity, NIRS is a physical non-destructive method, requiring minimal sample preparation, with high accuracy. In contrast to traditional chemical analyses, NIRS requires no reagents, producing no waste. It is furthermore a multi-analytical technique as several determinations can be made simultaneously and once the NIRS is calibrated, it is simple to use and operate (Givens et al., 1997). For example, conventional chemical analysis of feeds will take two to three days, while a similar analysis can be completed in 2 - 3 minutes by NIRS (Corson et al., 1999). However, calibration sets with insufficient distribution of the samples could lead to inaccurate calibrations (Viljoen et al., 2005).

The chemical composition of ostrich total mixed rations (TMRs) varies considerably due to the wide range of raw materials and by-products used. The prediction of the composition of compound feeds is 
generally less accurate compared to the calibrations to predict the chemical composition of raw materials. This is mainly because of the variation in range and quantity of raw materials which may exhibit different spectral characteristics for a compound feed with apparently the same chemical composition (Givens \& Deaville, 1999). Aufrère et al. (1996) stated that NIRS is not widely used for concentrates and compound feeds as a large number of samples are required for the calibration. Compound feeds are further spectrally complicated because of the wide choice of raw materials used in such feeds as an infinite number of combinations is possible (de Boever et al., 1995). In this study the possibility of using NIRS to predict the chemical composition of ostrich TMRs was examined.

\section{Materials and Methods}

A total of 479 ostrich TMRs were subjected for chemical analysis for dry matter (DM), ash, crude protein (CP), ether extract (EE), crude fibre (CF), acid detergent fibre (ADF), neutral detergent fibre (NDF), gross energy (GE), calcium (Ca) and phosphorus (P). The DM percentage of feeds was determined by loss of weight after drying a $2 \mathrm{~g}$ aliquot of each sample for 24 hours at $100{ }^{\circ} \mathrm{C}$ (AOAC, 2005). The ash content was determined by ashing an aliquot of the sample at $500{ }^{\circ} \mathrm{C}$ for 5 hours in a Labcon Muffle furnace RM7 (AOAC, 2003). Nitrogen (N) was analysed by using a Leco FP428 Nitrogen analyser according to the Dumas Combustion Method. A factor of 6.25 was used to estimate the CP content (AOAC, 2003). Analyses for NDF and ADF were carried out according to Goering \& Van Soest (1970). Neutral detergent fibre and CF were determined by using a Velp Scientifica FIWE Raw Fiber Extractor while ADF was determined by using a JP Selecta Dosi-Fiber Cellulose and Fibre Determination Extractor. Ether Extract was determined by a Soxtec system HT 1043, using diethyl-ether as an extraction fluid (AOAC, 2005). The Ca and P content of feeds were determined by Agri Laboratory Association of South Africa method number 6.1.1 using the dry ashing method and reading the samples on a Thermo Electron iCap 6000 series Inductively Coupled Spectrophotometer (ICP).

The sample population used in the calibration consisted of 479 ostrich TMR samples while 94 samples were used in the cross validation. The ostrich TMR samples selected for this study varied widely in their chemical composition, as feed samples of feeds used in different growth stages such as pre-starter; starter, grower and maintenance feeds were collected. Samples were ground through a $1 \mathrm{~mm}$ sieve and scanned in small ring cups. The samples were scanned in the reflectance mode between 1100 - 2500-nm of the nearinfrared region on an InfrAlyzer 500 near infrared reflectance spectrometer (IA-500) using Bran+Leubbe SESAME Version 2.00 software (Bran + Luebbe GmbH, Norderstedt, Germany). Calibrations were developed for the following chemical components: DM, ash, CP, EE, CF, ADF, NDF, GE, Ca and P. The calibration equations were independently validated on 94 TMR samples and outliers were removed, as suggested by the instrument.

The method relies on the measurement of light absorption by a feed sample when scanned using wavelengths in the near-infrared region (1100 - $2500 \mathrm{~nm}$ ) with reflectances measured (as log 1/reflectance) at 2-nm intervals to obtain the NIRS spectra. The resulting absorption spectrum depends on the chemical bonds within the components of the scanned sample and it is therefore possible to identify specific regions of the spectrum correlated with constituents such as starch, fibre or crude protein (Mould, 2003). Calibrations were developed by means of partial least-squares regression (PLSR). PLSR is the appropriate multivariate calibration technique to avoid the problem of the very high intercorrelation between absorbances (Goedhard, 1990).

\section{Results and Discussion}

The statistics of NIRS calibrations for chemical components are presented in Table 1. Coefficient of determination in validation $\left(r^{2}\right)$ and standard error of prediction (SEP) was satisfactory, i.e. $r^{2}$ higher than 0.80 for CP, EE, CF, ADF, NDF and GE with values being $0.97 \%$ and $0.74 \%, 0.89 \%$ and $0.50 \%, 0.94 \%$ and $1.41 \%, 0.89 \%$ and $2.67 \%, 0.95 \%$ and $2.81 \%$ and $0.80 \%$ and $0.28 \mathrm{MJ} / \mathrm{kg}$, respectively. It was less accurate $\left(r_{\mathrm{v}}^{2}\right.$ below 0.80) for DM, ash, Ca and P. Guidelines for interpretation of $r$, according to Williams (2001), state that a value of 0.83 to 0.90 for $r^{2}$ is usable in most applications, including quality assurance. A value of more than 0.98 is usable in any application while $r^{2}$ values of 0.66 to 0.81 can only be used for screening and possibly some other approximate applications. The calibrations for ash, Ca en $\mathrm{P}$ were poor because minerals 
do not absorb in the near infrared region, which corresponds with results reported by de Boever et al. (1995) for compound feeds for cattle.

The coefficient of correlation, $r$, indicates the closeness of fit between the NIRS reflectance and reference data over the range of composition. A high $r$ value with a low SEP and bias, together with a slope close to 1.0, means that the NIRS reflectance results are accurate over the anticipated range and likely to remain so, provided that these statistics were based on a sufficient number of observations (Williams, 2001).

Table 1 Statistics of the calibration equations, coefficient of correlation $\left(r^{2}\right)$, coefficient of determination of validation $\left(r_{\mathrm{v}}^{2}\right)$, standard error of calibration (SEC), standard error of performance (SEP), standard deviation/ standard error of cross validation ratio (SD/SECV), standard deviation (SD) and mean of actual laboratory values and NIRS predicted values

\begin{tabular}{lccccccccc}
\hline & \multicolumn{2}{c}{$\begin{array}{c}\text { Calibration set } \\
(\mathrm{n}=479)\end{array}$} & \multicolumn{3}{c}{$\begin{array}{c}\text { Validation set } \\
(\mathrm{n}=94)\end{array}$} & \multicolumn{3}{c}{$\begin{array}{c}\text { Actual Laboratory } \\
\text { values }\end{array}$} & \multicolumn{2}{c}{$\begin{array}{c}\text { NIRS predicted } \\
\text { values }\end{array}$} \\
\cline { 2 - 10 } $\begin{array}{l}\text { Chemical } \\
\text { component }\end{array}$ & $r^{2}$ & $\begin{array}{c}\text { SEC } \\
(\%)\end{array}$ & $r^{2}{ }_{\mathrm{v}}$ & $\begin{array}{c}\text { SEP } \\
(\%)\end{array}$ & $\begin{array}{c}\text { SD/SECV } \\
(\%)\end{array}$ & $\begin{array}{c}\text { Mean } \\
(\%)\end{array}$ & SD & $\begin{array}{c}\text { Mean } \\
(\%)\end{array}$ & SD \\
\hline & & & & & & & & & \\
DM & 0.77 & 0.63 & 0.57 & 0.28 & 5.59 & 91.26 & 1.57 & 91.24 & 1.03 \\
Ash & 0.87 & 0.79 & 0.67 & 1.29 & 1.74 & 9.52 & 2.24 & 9.43 & 1.93 \\
CP & 0.96 & 0.77 & 0.97 & 0.74 & 5.76 & 14.01 & 4.24 & 14.08 & 4.30 \\
EE & 0.93 & 0.37 & 0.89 & 0.50 & 2.96 & 2.74 & 1.48 & 2.73 & 1.46 \\
CF & 0.95 & 1.38 & 0.94 & 1.41 & 4.00 & 17.71 & 5.65 & 17.52 & 6.00 \\
ADF & 0.95 & 1.71 & 0.89 & 2.67 & 2.95 & 22.86 & 7.89 & 22.41 & 7.79 \\
NDF & 0.94 & 2.85 & 0.95 & 2.81 & 4.54 & 37.35 & 12.75 & 37.25 & 12.92 \\
GE & 0.87 & 0.22 & 0.80 & 0.28 & 2.23 & 15.96 & 0.62 & 15.97 & 0.62 \\
Ca & 0.75 & 0.42 & 0.43 & 0.59 & 1.26 & 1.94 & 0.74 & 1.86 & 0.67 \\
P & 0.74 & 0.09 & 0.49 & 0.11 & 1.37 & 0.68 & 0.15 & 0.68 & 0.14 \\
& & & & & & & & &
\end{tabular}

DM: dry matter; CP: crude protein; EE: ether extract; CF: crude fibre; ADF: acid detergent fibre; NDF: neutral detergent fibre; GE: gross energy; Ca: calcium; P: phosphorus.

The SD/SECV ratio represents the standard deviation of the chemical analyses divided by the standard error of cross validation of the calibration providing a comparison of the performance of all NIRS calibrations irrespective of the different units of the chemical parameters (Park et al., 1998). High values for the SD/SECV (ideally 5 or more, but at least 3) indicate efficient NIR reflectance predictions. The ratio between standard deviation/standard error of cross validation (SD/SECV), presented in Table 1, were the highest for DM and CP at 5.59 and 5.76 respectively. The lowest SD/SECV ratio was for Ca at 1.26. Calibrations for CF and NDF presented a SD/SECV ratio value of less than three, which is regarded as fair, while the SD/SECV ratio values for ash, EE, ADF, GE, Ca and P were poor. Xiccato et al. (2003), PérezMarín et al. (2004) and González-Martín (2006) obtained acceptable accurate calibrations for CP, EE and CF in compound feeds.

The relationship between laboratory determined and NIRS predicted values for CP, EE and CF is presented in Figure 1. Results of NIRS calibration indicate good correlations for CP, EE and CF with $r^{2}$ values higher than 0.81 . The high $r^{2}$ values for CP, EE and CF indicate very good predictive capability compared to DM, ash, Ca and P. The CP and EE predictions were satisfactory for calibration with SEP values of $0.74 \%$ and $0.50 \%$ and $r^{2}$ value of 0.97 and 0.89 , respectively. For CF values were $0.94 \%$ and $1.41 \%$ respectively. Bruno-Soares et al. (1998) also reported accurate predictions of CP and CF by NIRS, confirming the findings of the present study. NIRS is most successful when equations are used on sample sets other than those used in calibration development. Therefore, it is necessary to determine whether it is appropriate to analyse a new population with existing NIRS equations (Smith \& Flinn, 1991). 
(a)

\section{Crude protein}

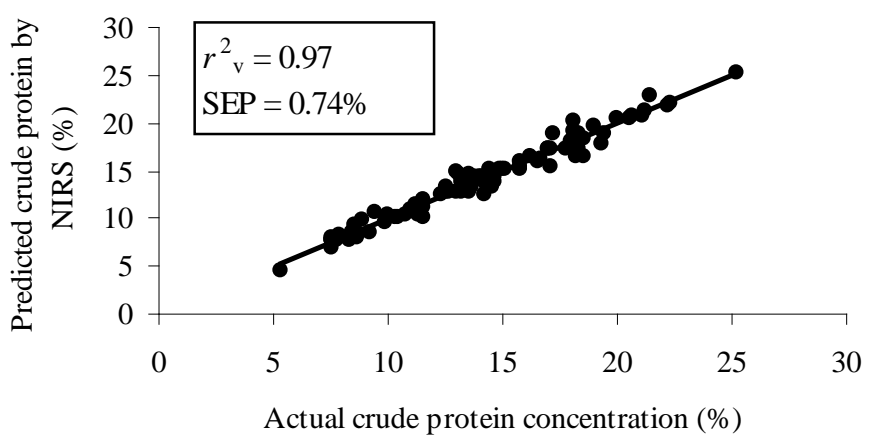

(b)

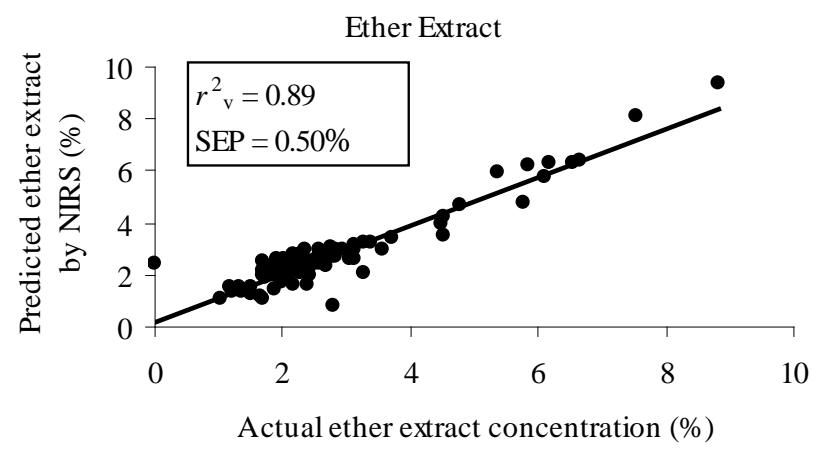

(c)

Crude Fibre

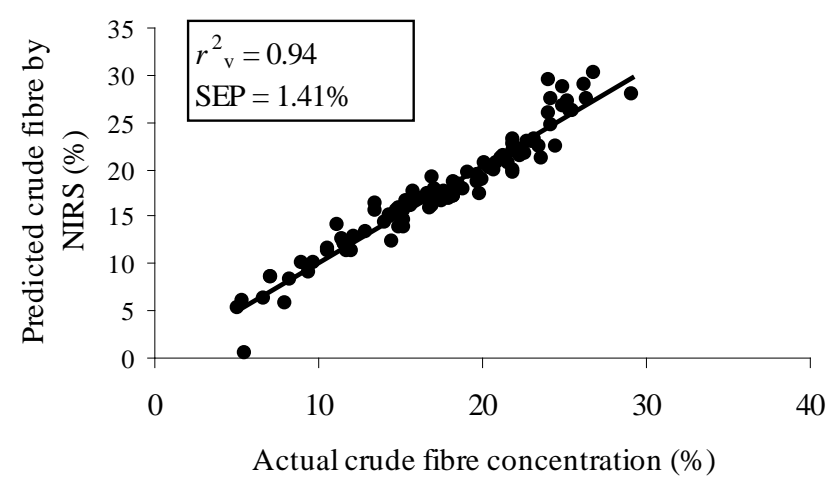

Figure 1 The relationship between laboratory determined and NIRS predicted values for (a) crude protein, (b) ether extract and (c) crude fibre.

\section{Conclusions}

It seems that good predictions can be obtained from the prediction for CP, EE, CF, ADF, NDF and GE of ostrich TMRs. Less accurate predictions for DM, ash, Ca and P were achieved for ostrich TMRs. Better calibrations will probably be obtained for the latter components if separate calibrations are developed for diets formulated for the different growth stages of ostriches. The study, however, indicates that NIRS is an accurate technique for the prediction of the most important chemical components in ostrich TMRs. 


\section{Acknowledgements}

The authors would like to thank A. Botha, S. September and F. Fransies at the Feeds Laboratory of the Department of Agriculture: Western Cape for the chemical analysis of the feed samples.

\section{References}

AOAC, 2005. Official Methods of Analysis. $18^{\text {th }}$ ed. Association of Official Analytical Chemists, Maryland, USA.

Aufrère, J., Graviou, D., Demarquilly, C., Perez, J.M. \& Andrieu, J., 1996. Near infrared reflectance spectroscopy to predict energy value of compound feeds for swine and ruminants. Anim. Feed Sci. Technol. 625, 77-90.

Bruno-Soares, A.M., Murray, I., Paterson, R.M. \& Abreu, J.M.F., 1998. Use of near infrared reflectance spectroscopy (NIRS) for the prediction of the chemical composition and nutritional attributes of green crop cereals. Anim. Feed Sci. Technol. 75, 15-25.

de Boever, J.L., Cottyn, B.G., Vanacker, J.M. \& Boucqué, Ch.V., 1995. The use of NIRS to predict the chemical composition and the energy value of compound feeds for cattle. Anim. Feed Sci. Technol. 51, 243-253.

Corson, D.C., Waghorn, M.J, Ulyatt, M.J. \& Lee, J., 1999. NIRS: Forage analysis and livestock feeding. Proc. N. Z. Grass. Assoc. 61, 127-132.

Givens, D.I. \& Deaville, E.R., 1999. The current and future role of near infrared reflectance spectroscopy in animal nutrition: A review. Aus. J. Agric. Res. 50, 1131-1145.

Givens, D.I., De Boever, J.L. \& Deaville, E.R., 1997. The principles, practices and some future applications of near infrared spectroscopy for predicting the nutritive value of foods for animals and humans. Nutr. Res. Rev. 10, 83-114.

Goedhart, P.W., 1990. Comparison of multivariate calibration methods for prediction of feeding value by near-infrared reflectance spectroscopy. Neth. J. Agric. Sci. 38, 449-460.

Goering, H.K. \& Van Soest, P.K., 1970. Forage Fiber Analyses (Apparatus, reagents, procedures and some applications). Agriculture Handbook no 379. ARS, USDA, Washington, D.C., USA.

González-Martín, I., Álvarez-García, N. \& Hernández-Andaluz, J.L., 2006. Instantaneous determination of crude proteins, fat and fibre in animal feeds using near infrared reflectance spectroscopy technology and a remote reflectance fibre-optic probe. Anim. Feed Sci. Technol. 128, 165-171.

Mould, F.L., 2003. Predicting feed quality - chemical analysis and in vitro evaluation. Field Crop Res. 84, 31-44.

Palic, D., 1998. Handbook of Feeds and Plant Analysis. Agri Laboratory Association of Southern Africa. Hatfield, Pretoria, South Africa.

Park, R.S., Agnew, R.E., Gordon, F.J. \& Steen, R.W.J., 1998. The use of near infrared reflectance spectroscopy (NIRS) on undried samples of grass silage to predict chemical composition and digestibility parameters. Anim. Feed Sci. Technol. 72, 155-167.

Pérez-Marín, D.C., Garrido-Varo, A, Gurerrero-Ginel, J.E. \& Gómez-Cabrera, A., 2004. Near-infrared reflectance spectroscopy (NIRS) for the mandatory labelling of compound feedingstuffs: chemical composition and open-declaration. Anim. Feed Sci. Technol. 116, 333-349.

Smith, K.F. \& Flinn, P.C., 1991. Monitoring the performance of a broad-based calibration for measuring the nutritive value of two independent populations of pasture using near infrared reflectance (NIR) spectroscopy. Aust. J. Exp. Agr. 31, 205-210.

Viljoen, M., Hoffman, L.C. \& Brand, T.S., 2005. Prediction of the chemical composition of freeze dried ostrich meat with near infrared reflectance spectroscopy. Meat Sci. 69, 255-261.

Williams, P.C., 2001. Implementation of near-infrared technology. In: Near-infrared Technology in the Agricultural and Food Industries, $2^{\text {nd }}$ ed. Eds Williams, P. \& Norris, K., St. Paul, USA: American Association of Cereal Chemists. pp. 145-169.

Xiccato, G., Trocino, A., De Boever, J.L., Maertens, L., Carabaño, R., Pascual, J.J., Perez, J.M., Gidenne, T. \& Falcao-E-Cunha, L., 2003. Prediction of chemical composition, nutritive value and ingredient composition of European compound feeds for rabbits by near infrared reflectance spectroscopy (NIRS). Anim. Feed Sci. Tech. 104, 153-168. 